\title{
Study of Stability and Structural Changes Occurring during High Thermal Load of the High Voltage Cathode Material by In Situ Scanning Electron Microscopy
}

\author{
T. Kazda ${ }^{1}$, L. Novák ${ }^{2}$, T. Vystavěl ${ }^{2}$, J. Stárek $^{2}$ and J. Vondrák ${ }^{1}$ \\ 1. Department of Electrical and Electronic Technology, Faculty of Electrical Engineering and \\ Communication, Brno University of Technology, Technická 10, 61600 Brno, Czech Republic \\ 2. FEI Company, Vlastimila Pecha 1282/12, 62700 Brno, Czech Republic
}

One of the most progressive battery systems which are used in portable devices, electric vehicles and energy storage systems are Li-Ion batteries. However, currently used cathode materials are close to their limits and in the coming years they are no longer able to meet growing energy demands. Many research groups focus their interest on modifications of existing cathode materials in order to improve their parameters. Some of them search for new types of cathode materials which could replace currently used cathode materials. The result of one of those efforts was the development of the cathode material $\mathrm{LiNi}_{0.5} \mathrm{Mn}_{1.5} \mathrm{O}_{4}$ [1]. This material is based on the $\mathrm{LiMn}_{2} \mathrm{O}_{4}$ where manganese is partially replaced by nickel, this allows to charge the cathode material up to $5 \mathrm{~V}$. Potential of $\mathrm{LiNi}_{0.5} \mathrm{Mn}_{1.5} \mathrm{O}_{4}$ against lithium is 4.7 $\mathrm{V}$ i.e. $1-1.5 \mathrm{~V}$ increase in respect to standard cathode materials. With this combination of high potential and theoretical capacity $148 \mathrm{mAh} / \mathrm{g}, \mathrm{LiNi}_{0.5} \mathrm{Mn}_{1.5} \mathrm{O}_{4}$ exhibits high gravimetric energy density approaching $700 \mathrm{Wh} / \mathrm{kg}$ which is approximately $20 \%$ more than gravimetric energy density of $\mathrm{LiCoO}_{2}$ and about $30 \%$ more than in the case of the cathode material $\mathrm{LiFePO}_{4}$. Moreover, $\mathrm{LiNi}_{0.5} \mathrm{Mn}_{1.5} \mathrm{O}_{4}$ is also stable during long term cycling and exhibits good stability at higher current loads because of the spinel structure; however, it still suffers by dissolution of manganese into the electrolyte during cycling at higher temperatures which leads to defects in the structure and capacity decrease [2].

This contribution deals with thermal properties of the $\mathrm{LiNi}_{0.5} \mathrm{Mn}_{1.5} \mathrm{O}_{4}$ synthesized by a solid-state reaction method. Thermal stability is one of the most important parameters characterizing cathode materials for Li-Ion batteries. Low thermal stability of cathode material can, in the worst case, cause fire of the battery pack like in the case of batteries in Boeing 787 Dreamliner [3]. Precursors based on carbonates and oxides were chosen as basic materials for the synthesis: $\mathrm{Li}_{2} \mathrm{CO}_{3}$ (Lithium(II) carbonate), $\mathrm{MnCO}_{3}$ (Manganese carbonate), $\mathrm{NiO}$ (Nickel oxide) were chosen. The two-step annealing process was selected for the preparation. In the first step, selected precursors were milled in the ball mill FRITSCH Pulverisette 0 for 4 hours, followed by annealing at $600{ }^{\circ} \mathrm{C}$ for 10 hours. The second step consists of annealing at $900{ }^{\circ} \mathrm{C}$ for 15 hours in oxygen atmosphere. Subsequently, the prepared cathode material was analysed in SEM and TGA (Thermogravimetric analysis) was used to test its thermal stability. The analysis was done in air atmosphere and monitored temperature range was set from room temperature to $900{ }^{\circ} \mathrm{C}$. The heating rate was set to $10{ }^{\circ} \mathrm{C} / \mathrm{min}$. The same thermal analysis was performed by using insitu SEM analysis on Quanta 250 FEG SEM. The experiment was carried out in environmental scanning electron microscopy mode (ESEM) with gaseous secondary electron detector (GSED) and with the $1000^{\circ} \mathrm{C}$ FEI heating stage. The heating rate was set to $10^{\circ} \mathrm{C} / \mathrm{min}$. Pressure in the microscope chamber was set to $200 \mathrm{~Pa}$, water vapor environment was used. The sample surface was imaged from room temperature to $700^{\circ} \mathrm{C}$ in $100^{\circ} \mathrm{C}$ steps, the sample was annealed for 15 minutes after reaching $700{ }^{\circ} \mathrm{C}$ and finally the specimen was cooled down to room temperature. The structure of the cathode material $\mathrm{LiNi}_{0.5} \mathrm{Mn}_{1.5} \mathrm{O}_{4}$ after synthesis is shown in Fig. $1-\mathrm{A}$ ). There are aggregates of small crystals in the entire volume. The average size of the crystals is smaller than $5 \mu \mathrm{m}$. The TGA analysis (Fig. 1-B) indicates that synthesized $\mathrm{LiNi}_{0.5} \mathrm{Mn}_{1.5} \mathrm{O}_{4}$ is very stable and there was no significant loss of weight up to 
$600{ }^{\circ} \mathrm{C}$. The sample also does not contain any water or carbon residuals, which could remain there after the synthesis. The weight decrease above $600{ }^{\circ} \mathrm{C}$ is typical for such high-voltage cathode materials; it is caused by losing oxygen and lithium from the cathode structure [4]. Fig. 2 shows development of the cathode structure during heating. There are no sample morphology changes during heating from the room temperature (Fig. 2-A) up to $500{ }^{\circ} \mathrm{C}$ (Fig. 2-C). Small cracks and holes are formed on the surface of some crystals below $600{ }^{\circ} \mathrm{C}$. These cracks and holes significantly enlarge after reaching $700{ }^{\circ} \mathrm{C}$ and during annealing at $700{ }^{\circ} \mathrm{C}$. These results confirm TGA measurement. In-situ SEM provides additional information about the collapse of cathode material caused by release of lithium and oxygen from its structure.

\section{References:}

[1] H. D. Yoo et al, Materials Today 17 (2014), p. 110.

[2] M. Hu, X. Pang, Z. Zhou, J of Power Sources 237 (2013), p. 229.

[3] W. Nicholas et al, Energies 6 (2013), p. 4682.

[4] K. J. Hong, Y. K. Sun, J of Power Sources 109 (2002), p. 427.
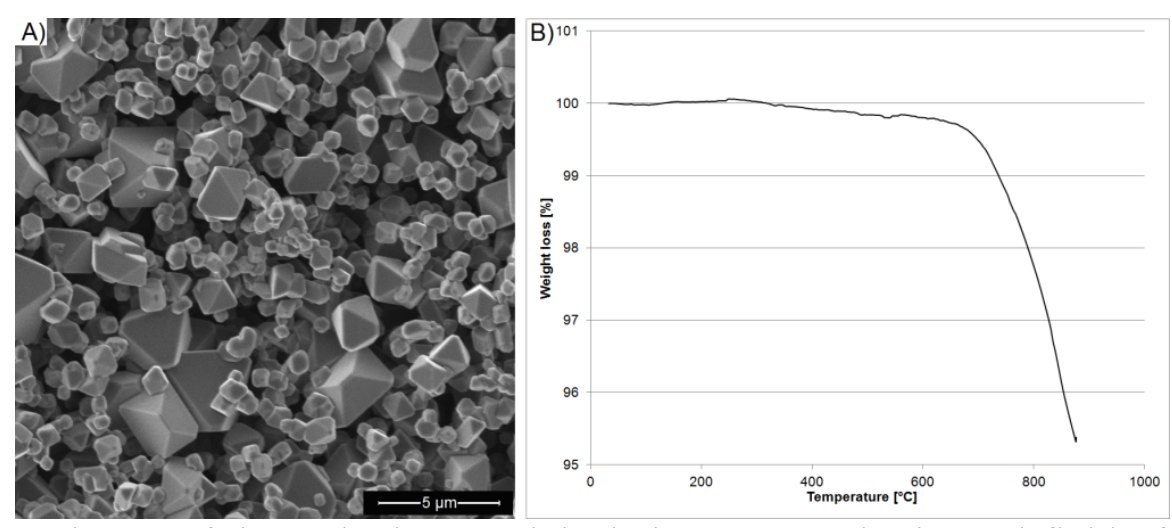

Figure 1. A) SEM picture of the cathode material $\mathrm{LiNi}_{0.5} \mathrm{Mn}_{1.5} \mathrm{O}_{4}$; horizontal field of view is $20.8 \mu \mathrm{m}$, B) TGA analysis of the cathode material $\mathrm{LiNi}_{0.5} \mathrm{Mn}_{1.5} \mathrm{O}_{4}$.

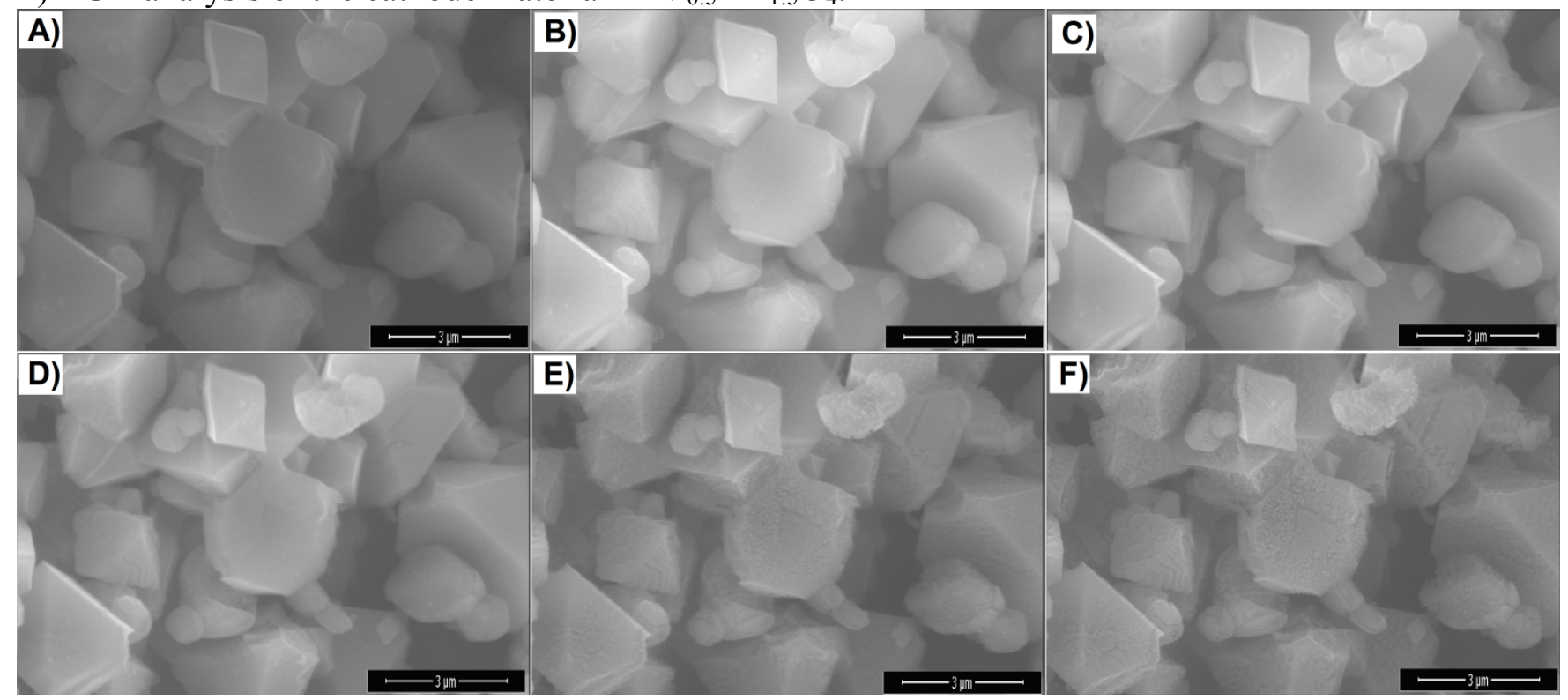

Figure 2. in situ SEM analysis of the cathode material $\mathrm{LiNi}_{0.5} \mathrm{Mn}_{1.5} \mathrm{O}_{4}$ during heating; A) $25{ }^{\circ} \mathrm{C}$, B) $\left.\left.400{ }^{\circ} \mathrm{C}, \mathrm{C}\right) 500{ }^{\circ} \mathrm{C}, \mathrm{D}\right) 600^{\circ} \mathrm{C}$ E) $\left.700{ }^{\circ} \mathrm{C}, \mathrm{F}\right) 700{ }^{\circ} \mathrm{C}$ after $15 \mathrm{~min}$, horizontal field width is $12.7 \mu \mathrm{m}$. 